\title{
Estudo da forma do fuste utilizando redes neurais artificiais e funções de afilamento
}

\author{
Ana Beatriz Schikowski ${ }^{1 *}$, Ana Paula Dalla Corte ${ }^{1}$, Carlos Roberto Sanquetta ${ }^{1}$ \\ ${ }^{1}$ Universidade Federal do Paraná, Departamento de Ciências Florestais, Av. Pref. Lothário Meissner, 900, Jardim Botânico - Campus III, CEP 80210-170, Curitiba, \\ PR, Brasil
}

"Autor correspondente:
anabeatrizschik@gmail.com

Termos para indexação:

Cubagem

Eucalipto

Inteligência artificial

Index terms:

Cubage

Eucalypt

Artificial intelligence

Histórico do artigo:

Recebido em 25/02/2015

Aprovado em 19/05/2015

Publicado em 30/06/2015

doi: 10.4336/2015.pfb.35.82.867
Resumo - As redes neurais artificiais (RNA) possuem grande potencial como alternativa à análise de regressão convencional, dada a capacidade de aprendizado de informações de um conjunto de dados e a generalização desse aprendizado para dados desconhecidos. Nesse sentido, o objetivo do presente trabalho foi utilizar RNAs para a estimativa do diâmetro relativo, volume total e comercial, bem como a comparação do desempenho em relação a funções de afilamento convencionais. Dados provenientes de 47 árvores de Eucalyptus sp. foram utilizados no treinamento e validação das RNAs e no ajuste das funções de afilamento de Hradetzky e Garay. O desempenho das RNAs foi muito semelhante ao das funções de afilamento na estimava do diâmetro relativo. As estimativas de volume total e comercial com RNAs se mostraram mais precisas e com menor dispersão dos resíduos que Hradetzky e Garay. RNAs se mostraram acuradas e adequadas para a estimativa de diâmetro relativo e volume.

\section{Study of stem form using artificial neural networks and taper functions}

\begin{abstract}
Artificial neural networks (ANN) have great potential as an alternative to conventional regression analysis because of its learning capacity of data set information and the generalization of learning to unknown data. So, the aim of this study was to apply RNAs to estimate relative diameter, total and commercial volume, as well as to compare their performance in relation to conventional taper functions. Data from 47 trees of Eucalyptus sp. were used in the training and validation of ANNs and in adjusting Hradetzky and Garay taper functions. The performance of ANNs were similar to the taper functions for diameter estimative, furthermore the estimative of commercial and total volume applying ANNs were more accurate and presented less residues scattering than Garay and Hradetzky function. ANNs were accurate and appropriate for the estimation of volume and relative diameter.
\end{abstract}




\section{Introdução}

A quantificação acurada do volume em povoamentos florestais para fins comerciais é de suma importância, sendo a cubagem o meio usual para esse fim. Como a quantificação por meio da cubagem é onerosa, se faz necessário aliar métodos indiretos para sua estimativa, sendo comumente utilizadas as equações de volume, funções de afilamento e fator de forma (Schröder et al., 2013), que tem como base as variáveis de fácil mensuração, como diâmetro a $1,30 \mathrm{~m}$ do solo (dap) e altura total, sendo representados por modelos rígidos, sem flexibilidade. Nesse sentido, as redes neurais artificiais (RNA) vem ganhando notoriedade no campo da estimação, sendo potencialmente útil na ciência florestal como uma alternativa à análise de regressão convencionalmente aplicada, dada à sua flexibilidade no treinamento e modelagem das relações entre variáveis (Binoti et al., 2014b).

RNA é um conjunto de técnicas não paramétricas, definidas como sistemas paralelos distribuídos, compostos por unidades de processamento matemático simples, os neurônios. Estas unidades são dispostas em uma ou mais camadas interligadas por um grande número de conexões, em um arranjo semelhante aos das redes neurais biológicas. Dado um conjunto de dados, as RNA têm a capacidade de aprendizado de informações obtidas pelo conjunto, visando posteriormente à generalização do conhecimento assimilado para um conjunto de dados desconhecidos. Possuem ainda a capacidade de extrair características não explícitas de um conjunto de informações que lhes são fornecidas (Braga et al., 2007; Gorgens et al., 2009; Silva et al., 2009; Binoti et al., 2014b). Assim sendo, uma rede neural é caracterizada pelo seu padrão de conexões entre os neurônios, ou seja, sua arquitetura; seu método de determinação dos pesos das conexões, a sua topologia ou aprendizagem; e a sua função de ativação (Özçelik et al., 2013).

A utilização de RNA como método estimativo na ciência florestal brasileira ainda é muito recente, praticamente exclusiva em estudos referentes a reflorestamentos, tais como estudos para estimativas do volume individual (Silva et al., 2009; Gorgens et al., 2009; Binoti et al., 2014b; Pelli et al., 2014; Silva et al., 2014), altura (Binoti et al., 2013; Freitas et al., 2014), do diâmetro relativo e estudo da forma (Leite et al., 2011; Soares et al., 2011; Souza, 2013). É necessário destacar que modelos de RNA geralmente se mostram superiores aos modelos de regressão linear ou não linear, devido à sua capacidade para superar problemas em dados da floresta, como por exemplo relações não lineares, distribuição não Gaussiana, multicolinearidade, outliers e ruído nos dados, problemas esses que a rigidez dos modelos convencionais não conseguem englobar e modelar adequadamente (Diamantopoulou, 2005; Diamantopoulou \& Milios, 2010; Özçelik et al., 2010), somada à facilidade de inclusão de variáveis categóricas no modelo.

Dado o potencial de uso das RNA como alternativa à regressão convencional, a presente pesquisa teve por objetivo a comparação do desempenho das redes neurais artificiais em relação a funções de afilamento usualmente utilizadas para a estimativa do diâmetro relativo ao longo do fuste e volume para Eucalyptus sp.

\section{Material e métodos}

Os dados utilizados na presente pesquisa provêm de plantios comerciais de Eucalyptus sp., localizados nos municípios de Carambeí, Dois Vizinhos e Toledo, no Paraná. Eram plantios destinados para fins de energia, implantados com espaçamento $3 \mathrm{~m} \times 2 \mathrm{~m}$ e idade variando de 3 a 7 anos. Foi realizada a cubagem rigorosa de 47 árvores utilizando o método de Hohenadl, com medição de diâmetro ao longo do fuste de maneira relativa, com base na altura total da árvore. Assim, foram medidos os diâmetros a $0 \%, 1 \%, 2 \%, 3 \%, 4 \%, 5 \%, 10 \%, 15 \%, 25 \%$, $35 \%, 45 \%, 50 \%, 55 \%, 65 \%, 75 \%, 85 \%$ e $95 \%$. Foram utilizadas 32 árvores para o ajuste das funções e treino das redes neurais, restando 15 indivíduos para validação dos modelos. Foi respeitado o mesmo número de árvores por idade na validação, sendo, três indivíduos para cada idade contida na base de dados.

Foram ajustadas as funções de afilamento de Hradetzky (Hradetzky, 1976) e Garay (Garay, 1979), sendo o modelo de Hradetzky comumente conhecido como polinômio de potências fracionárias. Os modelos foram ajustados no software Statistica ${ }^{\circledR} 10$, sendo Hradetzky (equação 1) ajustado utilizando o procedimento de regressão linear múltipla, método de seleção de variáveis Forward stepwise com potências variando de 0,01 a 25 . O modelo de Garay (equação 2) foi ajustado pelo método de estimativa de mínimos quadrados não linear com uso do algoritmo Levenberg-Marquardt.

$$
\text { Hradetzky }
$$

$$
\left(\frac{\mathrm{di}}{\mathrm{dap}}\right)=\beta_{0}+\beta_{1}\left(\frac{\mathrm{hi}}{\mathrm{ht}}\right)^{\mathrm{Fl}^{\mathrm{l}}}+\beta_{1}\left(\frac{\mathrm{hi}}{\mathrm{ht}}\right)^{\mathrm{p}^{2}}+\ldots+\beta_{\mathrm{n}}\left(\frac{\mathrm{hi}}{\mathrm{ht}}\right)^{\mathrm{PI}^{\mathrm{n}}}
$$




$$
\left.\left(\frac{\mathrm{di}}{\mathrm{dap}}\right)=\beta_{0} *\left(1+\beta^{*} \operatorname{Ln}\left(1-\beta_{2} *\left(\mathrm{hi}^{\beta_{3} *} \mathrm{ht}^{-\beta_{3}}\right)\right)\right)\right)
$$

Em que: di = diâmetro i ao longo do fuste $(\mathrm{cm})$; dap $=$ diâmetro a $1,3 \mathrm{~m}$ do solo $(\mathrm{cm}) ; \mathrm{hi}=$ altura $\mathrm{i}$ ao longo do fuste $(\mathrm{m}) ; \mathrm{ht}=$ altura total $(\mathrm{m}) ; \beta_{\mathrm{n}}=$ coeficientes do modelo; $\mathrm{Ln}=$ Logaritmo natural.

O volume do polinômio de Hradetzky foi obtido pela integração da função no software Maple ${ }^{\circledR} 13$. O volume do modelo de Garay foi obtido pelo método de Smalian, utilizando as estimativas dos diâmetros relativos ao longo do fuste em seções de $0,1 \mathrm{~m}$. O volume comercial foi determinado com base no fim comercial a que se destina a base de dados, no caso a indústria energética, sendo, calculado até o diâmetro da ponta fina - DPF igual a $8 \mathrm{~cm}$.

As RNAs foram treinadas no software NeuroForest ${ }^{\mathbb{B}}$ 3.2, utilizando as configurações de redes do tipo Multilayer Perceptron (MLP) ou perceptrons de múltiplas camadas, visto que conforme Hornik et al. (1989) esse tipo de rede possui capacidade universal de aproximação de funções. Detalhes sobre os fundamentos matemáticos aplicados nas redes fogem do escopo do presente trabalho e podem ser obtidos em Haykin (2001). O software permite a utilização de apenas uma camada oculta, mas conforme o "Teorema da aproximação universal", apenas uma camada oculta já é suficiente para uma rede MLP realizar a aproximação de qualquer função contínua (Cybenko, 1989; Haykin, 2001).

Foi utilizado o tipo de treinamento Resilient Propagation RPROP+, com função de ativação sigmoidal do tipo $\mathrm{f}(\mathrm{x})=1 /\left(1+\mathrm{e}^{-\mathrm{x}}\right)$. O algoritmo de treinamento Resilient Propagation, descrito por Riedmiller \& Braun (1993), representa uma variante do algoritmo backpropagation (retropropagação do erro), apresentando por vezes um resultado superior por seu ajuste de pesos depender mais do sinal dos gradientes de erro e não de sua magnitude (Riedmiller \& Braun, 1993).

A variação se deu na arquitetura da rede, testandose diferentes números de neurônios na camada oculta, variando de 1 a 15 neurônios. Como critério de parada no treinamento adotou-se a formatação padrão do programa, em que a RNA para o ajuste dos pesos ao atingir o erro médio de 0,0001 ou os 1.000 ciclos de treinamento. O programa NeuroForest trabalha com a metodologia de treinamento off-line, ou seja, os dados de treinamento não mudam, e caso ocorra mudança, um novo treinamento deve ser realizado.

A qualidade dos ajustes foi avaliada utilizando indicadores de ajuste como a correlação de Pearson (r) entre os valores observados e preditos, juntamente com a raiz quadrada do erro médio (RSME) (equação 3), bem como a análise gráfica dos resíduos e histograma de erros percentuais.

$$
\operatorname{RSME}=\frac{100}{\overline{\mathrm{Y}}} \sqrt{\left(\frac{\sum_{\mathrm{i}=1\left(\mathrm{Y}_{\mathrm{i}} \dot{Y}_{\mathrm{i}}\right)^{2}}^{\mathrm{n}}}{\mathrm{n}}\right)}
$$

Em que: $\mathrm{Y}=$ variável observada avaliada; $\hat{Y}=$ variável estimada; $\bar{Y}=$ média das variáveis observadas; $\mathrm{n}=$ número de observações.

Complementando o teste de acuracidade dos modelos de afilamento, foram utilizadas estatísticas adicionais que se baseiam em testes nos resíduos (equações 4 a 8), conforme metodologia indicada por Parresol et al. (1987) e Figueiredo Filho et al. (1996). Esse procedimento foi adotado pois os indicadores de ajuste anteriormente citados avaliam se os ajustes das funções de afilamento foram satisfatórios, ao passo que as estatísticas adicionais são calculadas para os resíduos de todas as seções relativas da cubagem.

$$
\begin{aligned}
& \mathrm{D}=\left(\sum \text { Diff }_{\mathrm{i}}\right) / \mathrm{n} \\
& |\mathrm{D}|=\left(\sum\left|\operatorname{Diff}_{\mathrm{i}}\right|\right) / \mathrm{n} \\
& \mathrm{SD}=\frac{\sqrt{\sum\left(\text { Diff }_{\mathrm{i}}^{2}\right)-\frac{\sum\left(\text { Diff }_{\mathrm{i}}^{2}\right)}{\mathrm{n}}}}{\mathrm{n}} \\
& \mathrm{SQRR}=\sum\left(\text { Diff }_{\mathrm{i}} / \mathrm{y}_{\mathrm{i}}\right)^{2} \\
& \mathrm{RP}=\sum\left(\operatorname{Diff}_{\mathrm{i}} / \mathrm{y}_{\mathrm{i}}\right)^{* * 100 / n}
\end{aligned}
$$

Onde: $\mathrm{D}$ = Desvio Médio; $|\mathrm{D}|=$ Desvio Médio Absoluto; $\mathrm{SD}$ = Desvio Padrão das Diferenças; $\mathrm{SQRR}=$ Soma do Quadrado do Resíduo Relativo; RP = Porcentagem dos Resíduos.

Em que: $\operatorname{Difr}_{\mathrm{i}}=\left(y_{\mathrm{i}}-\tilde{y_{1}}\right)$ desvio das variáveis observadas e estimadas; $\mathrm{y}_{1}=$ variável observada da arvore $\mathrm{i} ;{\widehat{y_{1}}}=$ variável estimada da árvore $\mathrm{i} ; \mathrm{n}=$ número de observações.

O desvio (D) indica a existência ou não de tendências entre os resíduos, porém não mede o quanto os valores 
residuais estão afastados do eixo zero. Já a porcentagem dos resíduos (RP) mostra a amplitude dos erros, o SSRR relaciona o tamanho de cada resíduo em relação ao seu valor real, e o desvio padrão das diferenças (SD) mostra a homogeneidade entre os resíduos (Parresol et al., 1987; Souza, 2009).

Os modelos foram ordenados em relação às estatísticas citadas, a fim de definir qual obteve o melhor desempenho em média. Esta análise foi feita por atribuição de notas, sendo a menor nota dada ao melhor modelo da referida estatística. Portanto, o que apresentou o menor somatório foi considerado o de melhor desempenho. A análise gráfica dos resíduos teve por objetivo ratificar a decisão do ranqueamento, bem como identificar possíveis tendências ao longo da linha estimativa.

\section{Resultados e discussão}

Na Tabela 1 estão apresentadas as estatísticas descritivas dos indivíduos amostrados, com seus valores de dap, altura e volume médios, bem como o respectivo desvio padrão de cada variável.

Tabela 1. Estatísticas descritivas dos indivíduos de Eucalyptus sp. amostrados.

\begin{tabular}{ccccc}
\hline Idade & $\begin{array}{c}\text { Número de } \\
\text { indivíduos }\end{array}$ & dap $(\mathbf{c m})$ & $\begin{array}{c}\text { Altura total } \\
(\mathbf{m})\end{array}$ & Volume total $\left(\mathbf{m}^{3}\right)$ \\
\hline 3 & 7 & $13,1( \pm 2,4)$ & $15,1( \pm 2,2)$ & $0,106( \pm 0,05)$ \\
4 & 7 & $17,0( \pm 2,6)$ & $16,0( \pm 3,3)$ & $0,177( \pm 0,09)$ \\
5 & 12 & $17,0( \pm 5,2)$ & $20,9( \pm 6,4)$ & $0,274( \pm 0,22)$ \\
6 & 12 & $24,9( \pm 3,0)$ & $28,6( \pm 6,8)$ & $0,646( \pm 0,28)$ \\
7 & 9 & $26,1( \pm 3,6)$ & $32,9( \pm 3,8)$ & $0,816( \pm 0,29)$ \\
\hline Total & 47 & $20,2( \pm 6,1)$ & $23,6( \pm 8,4)$ & $0,434( \pm 0,35)$ \\
\hline
\end{tabular}

Valores entre parênteses são o desvio padrão de cada variável.

\section{Estimativa do diâmetro relativo ao longo do fuste}

Na Tabela 2 são apresentados os coeficientes dos modelos de Hradezky e Garay, bem como as potências selecionadas pelo método stepwise. Representa ainda a arquitetura das redes neurais testadas juntamente com as variáveis de entrada no modelo.

O processo de determinação do número de neurônios da camada oculta, em conjunto com o número de ciclos definido, pode resultar em dois fenômenos distintos: um número excessivo de neurônios resulta no processo conhecido como overfitting, em que ocorre a memorização dos dados de treinamento, acarretando em valores muito baixos do RSME no treinamento e valor crescente do RSME para o conjunto de validação. Ao passo que um pequeno número de neurônios acarreta o processo contrário, underfitting, em que o reduzido número de neurônios não consegue realizar a tarefa desejada, ou seja, não consegue explicar a variação do conjunto de dados de treinamento (Silva et al., 2010; Binoti et al., 2014a). A escolha do número de neurônios da camada oculta foi realizada seguindo esse direcionamento, em que foi observada a ineficiência ou mesmo a não capacidade de ajuste quando na presença de poucos neurônios na camada intermediária, bem como RSME crescente com muitos neurônios na camada oculta.

Realizado o ranking dos modelos quanto aos indicadores estatísticos na estimativa do diâmetro relativo do fuste, foi constatado que as redes neurais obtiveram melhor desempenho que os modelos convencionais de afilamento, sendo a RNA 1 de melhor desempenho, seguida por RNA 3, RNA 2, modelo de Garay e por último Hradetzky. Destaca-se que as RNAs treinadas apresentaram desempenho mais modesto que os modelos convencionais no momento das estatísticas da validação, porém essas diferenças são de pequena magnitude (Tabela 3).

Tabela 2. Coeficientes das funções de afilamento avaliadas e arquitetura das RNA de melhor desempenho.

\begin{tabular}{|c|c|c|c|c|}
\hline \multicolumn{5}{|c|}{ Hradetzky } \\
\hline Potencias Selecionadas & 0,8 & 0,01 & 4 & 5 \\
\hline Coeficientes & $1,328^{* *}-0,268^{* *}$ & $7,391^{* *}-7,903^{* *}$ & $-1,956^{* *}$ & $1,519^{* *}$ \\
\hline \multicolumn{5}{|c|}{ Garay } \\
\hline Coeficientes & $1,308^{* *} 0,238^{* *}$ & $0,994^{* *} 0,169^{* *}$ & - & - \\
\hline \multicolumn{5}{|c|}{ Redes } \\
\hline & Rede 1 & Rede 2 & \multicolumn{2}{|c|}{ Rede 3} \\
\hline Variáveis de entrada & $\mathrm{Ht}$; h; dap & $\mathrm{h} / \mathrm{Ht}$; dap & \multicolumn{2}{|c|}{$\mathrm{h} / \mathrm{Ht} ;(\mathrm{h} / \mathrm{Ht})^{2} ;$ dap } \\
\hline Arquitetura & $3: 7: 1$ & $2: 6: 1$ & \multicolumn{2}{|c|}{$3: 8: 1$} \\
\hline
\end{tabular}

$\mathrm{H}=$ altura total, $\mathrm{h}=$ altura relativa; dap $=$ diâmetro a $1,30 \mathrm{~m}$ do solo; $* *$ significativo a $99 \%$ de probabilidade pelo teste $t$.

Conforme observado nas estatísticas de ajuste, as diferentes variáveis de entrada nas RNAs para a estimativa do di não demonstraram melhora na estimativa, ainda que todos tenham apresentado precisão satisfatória. A mesma tendência foi apontada por Souza (2013), testando diversas entradas e combinações de dap, hi e ht para a estimativa do di via RNAs.

Binoti et al. (2014a) observou pouca variação nas estimativas volumétricas para Eucalyptus spp. via RNAs ou modelo Schumacher e Hall, mas aponta como vantagem que dada a possibilidade de inclusão de variáveis categóricas nas RNAs, uma rede pode explicar a variação volumétrica em relação a mais de 50 modelos 
volumétricos ajustados, visto que a base de dados utilizada pelos autores era muito ampla, necessitando de estratificação para a regressão convencional.

Souza (2013) no estudo do desempenho das RNAs para afilamento de Eucalyptus sp. aponta valores similares das correlações entre valores preditos e observados, porém RMSE mais elevados que os apresentados na presente pesquisa.

Em relação aos resíduos na estimativa de di, observase na Figura 1 que todos os modelos, tanto afilamento quanto RNA, apresentaram dificuldade em retratar a porção final do fuste, com menores valores de diâmetro.
Essa dificuldade é frequentemente reportada nos estudos de forma do fuste, tanto para as RNAs (Leite et al., 2011; Souza, 2013), quanto para os modelos convencionais de afilamento (Silva et al., 2011; Favalessa et al., 2012; Yoshitani Junior et al., 2012; Téo et al., 2013).

A maior porção dos resíduos está entre o intervalo de $-4 \%$ e $4 \%$, que representam os centros de classe dos resíduos, porém pode-se observar que nas estimativas via RNAs, os resíduos se concentraram na classe de centro $0 \%$, portanto a maior parte dos resíduos das redes estão entre $-2 \%$ e $2 \%$.

Tabela 3. Estatísticas do desempenho das funções de afilamento e RNAs treinadas para a estimativa do diâmetro relativo ao longo do fuste.

\begin{tabular}{ccccccccc}
\hline \multirow{6}{*}{ Treino } & & r & RMSE $_{\%}$ & D & $|\mathbf{D}|$ & SD & SSRR & RP \\
\hline \multirow{6}{*}{ Hradetzky } & 0,991 & 6,757 & $-0,116$ & 0,836 & 0,042 & 3,617 & 5,819 \\
& Garay & 0,991 & 6,495 & 0,090 & 0,794 & 0,031 & 3,818 & 5,827 \\
& RNA 1 & 0,992 & 5,748 & $-0,005$ & 0,707 & 0,035 & 3,190 & 5,164 \\
& RNA 2 & 0,992 & 5,780 & $-0,003$ & 0,714 & 0,032 & 3,370 & 5,344 \\
& RNA 3 & 0,992 & 5,672 & 0,001 & 0,702 & 0,039 & 3,135 & 5,300 \\
\hline \multirow{6}{*}{ Validação } & Hradetzky & 0,995 & 6,230 & $-0,249$ & 0,742 & 0,032 & 1,070 & 5,186 \\
& Garay & 0,994 & 5,483 & $-0,055$ & 0,688 & 0,034 & 1,100 & 5,146 \\
& RNA 1 & 0,994 & 5,302 & $-0,155$ & 0,642 & 0,030 & 1,031 & 4,816 \\
& RNA 2 & 0,994 & 5,360 & $-0,224$ & 0,687 & 0,030 & 1,149 & 5,292 \\
& RNA 3 & 0,993 & 5,801 & $-0,214$ & 0,694 & 0,029 & 1,470 & 5,392 \\
\hline
\end{tabular}

$\mathrm{r}=$ Correlação entre valor real e estimado; $\mathrm{RMSE}=$ Raiz quadrada do erro médio em porcentagem; $\mathrm{D}=$ Desvio médio; $|\mathrm{D}|$ = Desvio médio absoluto; $\mathrm{SD}$ = Desvio padrão das diferenças; $\mathrm{SSRR}=$ Soma do quadrado do resíduo relativo; $\mathrm{RP}=$ Porcentagem dos resíduos.

\section{Estimativa do volume total e comercial}

As estatísticas de ajuste para o volume total e comercial estão apresentadas na Tabela 4. Observa-se que os valores das estatísticas são muito próximos, dado o bom desempenho tanto dos modelos de afilamento quanto da RNA treinada. Quanto ao ranqueamento, o modelo de Hradetzky e a RNA treinada obtiveram comportamento similar, ambos superiores ao modelo de Garay. Destaca-se que a rede treinada possui a arquitetura de 2:5:2, em que foram usadas como variáveis de entrada o dap e altura total e duas saídas, o volume total e o volume comercial.

Na Figura 2 observa-se uma distribuição dos resíduos menos uniforme do que dos resíduos obtidos para a estimativa do diâmetro relativo, demonstrando assim a maior dificuldade dos modelos, tanto de afilamento quanto da rede, na estimativa do volume, sendo mais acentuada para a estimativa do volume comercial.

Segundo Schroder et al. (2013), as funções de afilamento demonstram ser confiáveis para a estimativa dos volumes total e comercial em detrimento das funções convencionais de volume. Este resultado também foi verificado na presente pesquisa, ainda que ocorra maior dispersão dos resíduos do volume. As RNAs também são indicadas para esse fim, desde que devidamente alimentadas com dados no treinamento. 

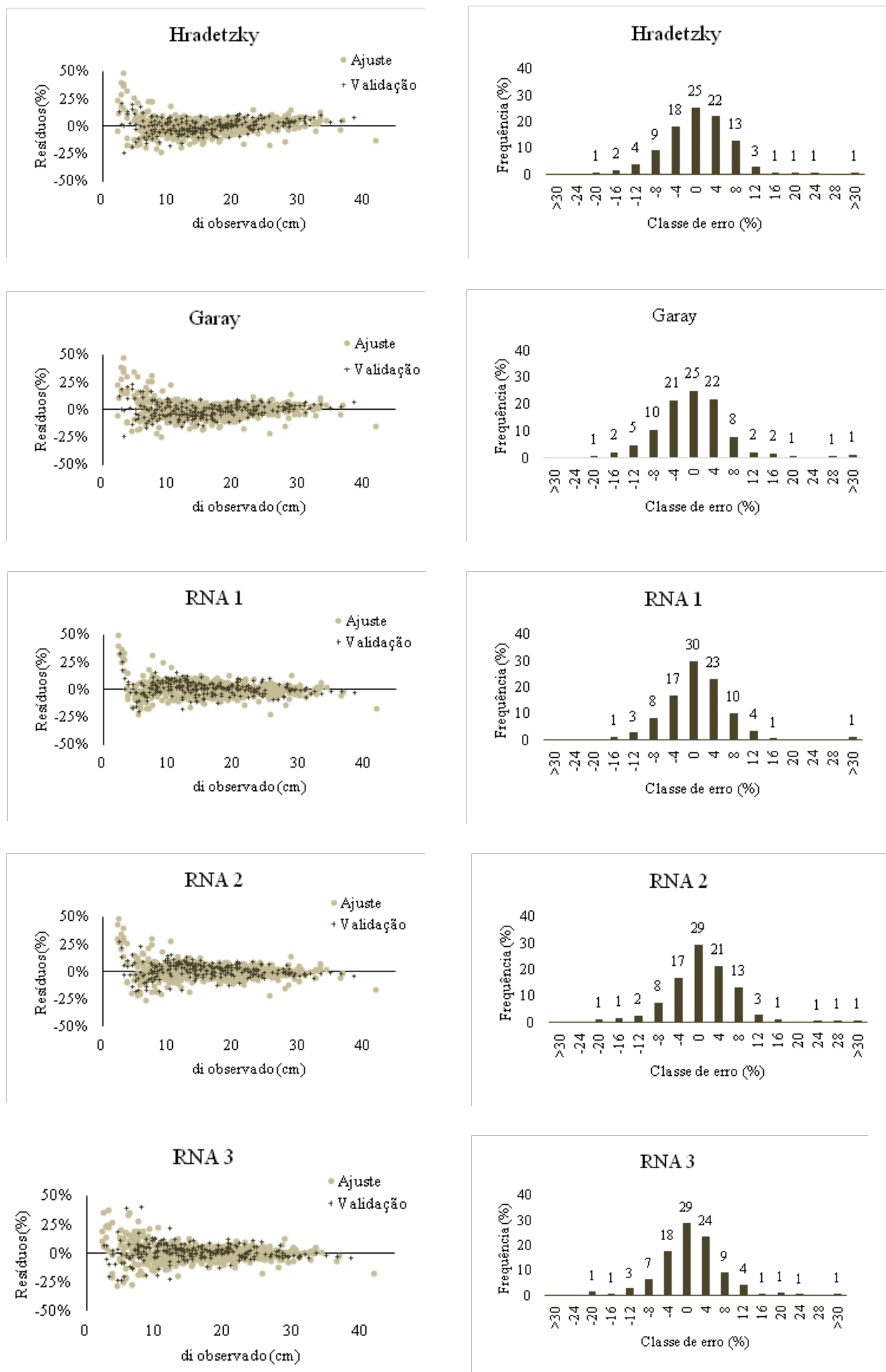

Figura 1. Dispersão dos resíduos percentuais em função do diâmetro ao longo do fuste observado e frequência dos resíduos estimados. 


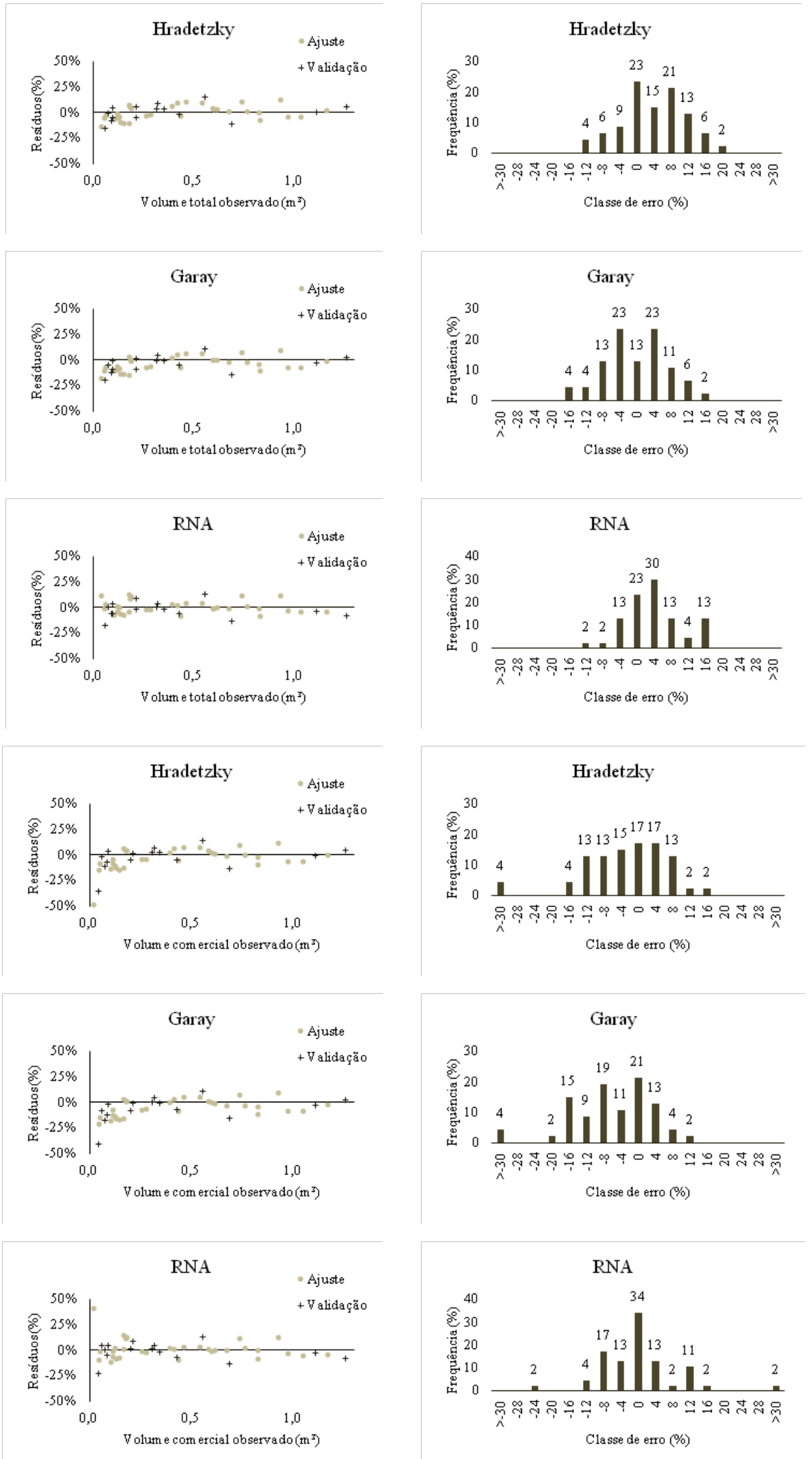

Figura 2. Dispersão dos resíduos percentuais em função do volume total do fuste observado, volume comercial e respectivas frequências dos resíduos. 
Tabela 4. Estatísticas do desempenho das funções de afilamento e RNAs treinadas para a estimativa do volume total do fuste e volume comercial $(\mathrm{DPF}=8 \mathrm{~cm})$.

\begin{tabular}{|c|c|c|c|c|c|c|c|c|c|}
\hline & & & $\mathbf{r}$ & $\mathbf{R M S E}_{\%}$ & D & $|\mathbf{D}|$ & SD & SSRR & RP \\
\hline \multirow{6}{*}{ Total } & \multirow{3}{*}{ Treino } & Hradetzky & 0,995 & 7,867 & $-0,007$ & 0,024 & 0,005 & 0,151 & 5,814 \\
\hline & & Garay & 0,995 & 7,757 & 0,010 & 0,024 & 0,005 & 0,209 & 6,618 \\
\hline & & RNA & 0,995 & 7,283 & $-8 * 10^{-6}$ & 0,020 & 0,005 & 0,117 & 4,747 \\
\hline & \multirow{3}{*}{ Validação } & Hradetzky & 0,996 & 9,607 & $-0,010$ & 0,024 & 0,008 & 0,089 & 6,317 \\
\hline & & Garay & 0,996 & 8,369 & 0,005 & 0,020 & 0,007 & 0,103 & 6,257 \\
\hline & & RNA & 0,995 & 10,591 & 0,010 & 0,026 & 0,009 & 0,093 & 6,146 \\
\hline \multirow{6}{*}{ Comercial } & \multirow{3}{*}{ Treino } & Hradetzky & 0,994 & 7,983 & 0,002 & 0,024 & 0,005 & 0,430 & 8,003 \\
\hline & & Garay & 0,994 & 8,472 & 0,013 & 0,026 & 0,005 & 0,583 & 9,194 \\
\hline & & RNA & 0,995 & 7,851 & $-6^{*} 10^{-6}$ & 0,021 & 0,005 & 0,315 & 6,298 \\
\hline & \multirow{3}{*}{ Validação } & Hradetzky & 0,996 & 9,568 & $-0,004$ & 0,023 & 0,008 & 0,195 & 7,745 \\
\hline & & Garay & 0,996 & 8,962 & 0,006 & 0,022 & 0,007 & 0,262 & 8,628 \\
\hline & & RNA & 0,995 & 10,422 & 0,008 & 0,025 & 0,009 & 0,113 & 6,552 \\
\hline
\end{tabular}

\section{Conclusão}

As RNAs treinadas apresentaram precisão similar ou superior aos modelos Hradetzky e Garay, tradicionalmente aplicados no estudo da forma das árvores, podendo ser indicadas para tal fim.

\section{Referencias}

BINOTI, D. H. B.; BINOTI, M. L. M. S.; LEITE, H. G. Configuração de redes neurais artificiais para estimação do volume de árvores. Ciência da Madeira, Pelotas, v. 5, n. 1, p. 58-67, 2014a.

BINOTI, M. L. M. S.; BINOTI, D. H. B.; LEITE, H. G. Aplicação de redes neurais artificiais para estimação da altura de povoamentos equiâneos de eucalipto. Revista Árvore, Viçosa, MG, v. 37, n. 4, p. 639-645. 2013. DOI: 10.1590/S0100-67622013000400007

BINOTI, M. L. M. S.; BINOTI, D. H. B.; LEITE, H. G.; GARCIA, S. L. R.; FERREIRA, M. Z.; RODE, R.; SILVA, A. A. L. Redes neurais artificiais para estimação do volume de árvores. Revista Árvore, Viçosa, MG, v. 38, n. 2, p. 283-288, 2014b. DOI: 10.1590/ S0100-67622014000200008

BRAGA, A. P.; CARVALHO, A. P. L. F.; LUDEMIR, T. B. Redes neurais artificiais: teoria e aplicações. 2. ed. Rio de Janeiro: LTC, 2007. $260 \mathrm{p}$.

CYBENKO, G. V. Approximation by superpositions of a sigmoidal function: mathematics of control. Signals and Systems, v. 2, n. 4, p. 303-314, 1989.

DIAMANTOPOULOU, M. J. Artificial neural networks as an alternative tool in pine bark volume estimation. Computers and Electronics in Agriculture, v. 48, n. 3, p. 235-244. 2005. DOI: 10.1016/j.compag.2005.04.002
DIAMANTOPOULOU, M. J.; MILIOS, E. Modelling total volume of dominant pine trees in reforestations via multivariate analysis and artificial neural network models. Biosystems Engineering. v. 105, n. 3, p. 306-315, 2010. DOI: 10.1016/j.biosystemseng.2009.11.010

FAVAlESSA, C. M. C.; UBIALli, J. A.; CALDEIRA, S. F.; DRESCHER, R.; ACOSTA, F. C. Equações de sortimentos para Tectona grandis na região centro - sul de Mato Grosso. Pesquisa Florestal Brasileira, Colombo, v. 32, n. 72, p. 389-399, 2012. DOI: 10.4336/2012.pfb.32.72.373

FIGUEIREDO FILHO, A.; BORDERS, B. E.; HITCH, K. L. Taper equations for Pinus taeda in southern Brazil. Forest Ecology and Management, Amsterdam, v. 83, n. 1-2, p. 39-46, 1996. DOI: 10.1016/0378-1127(96)03706-1

FREITAS, G. C.; SOUZA, E. G.; NOGUEIRA, G. S.; OLIVEIRA, M. L. R.; ALVES, P. H. BARBOSA, G. P. Estimativa hipsométrica de Tectona grandis no município de Morro da Garça - MG, utilizando modelos e redes neurais artificiais. In: CORTE, A. P. D.; SANQUETTA, C. R.; RODRIGUES, A. L.; MACHADO, S. A.; PÉLLICO NETTO, S.; FIGUEIREDO FILHO, A.; NOGUEIRA, G. S. (Org.). Atualidades em mensuração florestal. Curitiba: Multigraphics, 2014. v. 1. p. 344-348.

GARAY, L. Tropical forest utilization system. In: A tree $\mathbf{A}$ taper model for entire stem profile including buttressing. Seatlhe: College of Forest Resources, Institute of Forest Products, University of Washington, 1979. 64 p. (contrib. 36).

GORGENS, E. B.; LEITE, H. G.; GLERIANI, J. M.; SOARES, C. P. B.; CEOLIN, A. Estimação do volume de árvores utilizando redes neurais artificiais. Revista Árvore, Viçosa, MG, v. 33, n. 6, p. 11411147, 2009. DOI: 10.1590/S0100-67622009000600016

HAYKIN, S. S. Redes neurais: princípios e prática. 2. ed. Porto Alegre: Bookman, 2001. 900 p. 
HORNIK, K.; STINCHCOMBE, M.; WHITE, H. Multilayer feed forward network are universal approximators. Neural Networks, Bandera, v. 2, n. 5, p. 359-366, 1989.

HRADETZKY, J. Analyse und interpretation statistisher abräanger Keiten (Biometrische Beiträge zu aktuellen forschungs projekten). Baden: Württemberg Mitteilungen der FVA, 1976. (Abt. Biometric und Informatik, 21).

LEITE, H. G.; SILVA, M. L. M.; BINOTI, D. H. B.; FARDIN, L.; TAKIZA, WA F. H. Estimation of inside-bark diameter and heartwood diameter for Tectona grandis Linn. trees using artificial neural networks. European Journal of Forest Research, v. 130, n. 2, p. 263-269, 2011. DOI: 10.1007/s10342-010-0427-7

ÖZÇELIK, R.; DIAMANTOPOULOU, M. J.; BROOKS, J. R.; WIANT JR, H. V. Estimating tree bole volume using artificial neural network models for four species in Turkey. Journal of Environmental Management. v. 91, n. 3, p. 742-753, 2010. DOI: 10.1016/j.jenvman.2009.10.002

ÖZÇELIK, R.; DIAMANTOPOULOU, M. J.; CRECENTECAMPO, F.; ELER, U. Estimating Crimean juniper tree height using nonlinear regression and artificial neural network models. Forest Ecology and Management, Amsterdam, v. 306, p. 52-60, 2013. DOI: 10.1016/j.foreco.2013.06.009

PARRESOL, B. R.; HOTVEDT, J. E.; CAO, Q. V. A volume and taper prediction system for bald cypress. Canadian Journal of Forest Research, Ottawa, v. 17, p. 250-259, 1987.

PELli, E.; NOGUEIRA, G. S.; HORTA, E. G.; PAUlA, H. Estimativa de volume de árvores utilizando redes neurais artificiais. In: CORTE, A. P. D.; SANQUETTA, C. R.; RODRIGUES, A. L.; MACHADO, S. A.; PÉLLICO NETTO, S.; FIGUEIREDO FILHO, A.; NOGUEIRA, G. S. (Org.). Atualidades em mensuração florestal. Curitiba: Multigraphics, 2014, v. 1. p. 336-339.

RIEDMILLER, M.; BRAUN, H. A direct adaptive method for faster backpropagation learning: The RPROP algorithm. In: RUSPINI, $\mathrm{H}$. (Ed.). Proceedings of the IEEE International Conference on Neural Networks (ICNN). San Francisco, 1993. p. 586-591. DOI: 10.1109/ICNN.1993.298623

SCHRÖDER, T.; PEREIRA, L. D.; HOFIÇO, N. S. A. Comparação de métodos de estimativa de volume total para Eucalyptus grandis W. Hill ex Maiden. Floresta e Ambiente, Rio de Janeiro. v. 20, n.4, p. 480-486, 2013. DOI: 10.4322/floram.2013.041

SCHRÖDER, T.; HOFIÇO, N. A. S.; ZIMMERMANN, A. P. L.; PEREIRA, L. D.; ROCHA JUNIOR, D. S.; MEYER, E. A.; FLEIG, F. D. Métodos de estimativa de volume comercial para Eucalyptus grandis: especificidades e recomendações. Pesquisa Florestal Brasileira, Colombo, v. 33, n. 73, p. 1-7, 2013. DOI: 10.4336/2013. pfb.33.73.446
SILVA, F.; CORTE, A. P. D.; SANQUETTA, C. R. Equações de afilamento para descrever o volume total do fuste de Pinus caribaea var. hondurensis na região do Triângulo Mineiro. Scientia Forestalis, Piracicaba, v. 39, n. 91, p. 367-376, 2011.

SILVA, I. N.; SPATTI, H. D.; FLAUZINO, R. A. Redes neurais artificiais: para engenharia e ciências aplicadas. São Paulo: Artliber, 2010. 399 p.

SILVA, M. L. M.; BINOTI, D. H. B.; GLERIANI, J. M.; LEITE, H. G. Ajuste do modelo de Schumacher e Hall e aplicação de redes neurais artificiais para estimar volume de árvores de eucalipto. Revista Árvore, Viçosa, MG, v. 33, n. 6, p. 1133-1139, 2009. DOI: 10.1590/S0100-67622009000600015

SILVA, P. V.; ARAÚJO, A. C. S. C.; MARTINS, E. R.; BINOTI, M. L. M. S.; BINOTI, D. H. B.; LEITE, H. G. Estimação do volume de árvores de eucalipto utilizando redes neurais artificiais. In: CORTE, A. P. D.; SANQUETTA, C. R.; RODRIGUES, A. L.; MACHADO, S. A.; PÉLLICO NETTO, S.; FIGUEIREDO FILHO, A.; NOGUEIRA, G. S. (Org.). Atualidades em mensuração florestal. Curitiba: Multigraphics, 2014, v. 1. p. 84-87.

SOARES, F. A. A. M. N.; FLÔRES, E. L.; CABACINHA, C. D.; CARRIJO, G. A.; VEIGA, A. C. P. Recursive diameter prediction and volume calculation of Eucalyptus trees using multilayer perceptron networks. Computers and Electronics in Agriculture, v. 78, n. 1, p. 19-27, 2011. DOI: 10.1016/j.compag.2011.05.008

SOUZA, C. A. M. Modelos de afilamento para Pinus taeda $\mathbf{L}$. ajustados segundo a forma do tronco e métodos de estratificação. 2009. 120 f. Tese (Doutorado em Engenharia Florestal) - Universidade Federal de Santa Maria, Santa Maria, RS.

SOUZA, R. R. Estudo da forma do fuste de árvores de eucalipto em diferentes espaçamentos. 2013. 86 f. Dissertação (Mestrado em Engenharia Florestal) - Universidade Federal dos Vales do Jequitinhonha e Mucuri, Diamantina.

TÉO, S. J.; MARCON, A.; EHLERS, T.; BIANCHI, J. C.; PELOSO, A.; NAVA, P. R.; COSTA, R. H. Modelos de afilamento para Pinus elliottii em diferentes idades, na região de Caçador, SC. Floresta, Curitiba, v. 43, n. 3, p. 439-452, 2013. DOI: 10.5380/rf.v43i3.30320

YOSHITANI JUNIOR, M.; NAKAJIMA, N. Y.; ARCE, J. E.; MACHADO, S. A.; DRUSZCZ, J. P.; HOSOKAWA, R. T.; MELLO, A. A. Funções de afilamento para plantios desbastados de Pinus taeda. Floresta, Curitiba, v. 42, n. 1, p. 169-176, 2012. DOI: 10.5380/ rf.v42i1.26315 
